\title{
An Environmental Study on the Paid Plastic Bag Use Policy in the city of Semarang
}

\author{
Muhammad Muslihun ${ }^{1 *}$, Didi Dwi Anggroro², Kismartini $\mathrm{K}^{3}$ \\ ${ }^{1}$ Master Program of Environmental Studies, School of Postgraduate Studies Diponegoro University, \\ Semarang, Indonesia \\ ${ }^{2}$ Chemical Engineering Department, Faculty of Engineering Diponegoro University, Semarang, \\ Indonesia \\ ${ }^{3}$ Public Administration Department, Faculty of Social and Political Science, Diponegoro University, \\ Semarang, Indonesia
}

\begin{abstract}
Indonesia is the second largest contributor of plastic waste in the ocean. The initiative of the central government through KLHK in reducing the generation of plastic waste is to launch a paid plastic bag policy. This policy is regulated by a circular issued by KLHK to local governments and business actors. The purpose of this study is to analyse the implementation of policies, analyse consumer behaviour and analyse the supporting and inhibiting factors in the paid plastic bag policy which is applied in the city of Semarang. The approach used in this study is a qualitative approach. Data collection uses primary and secondary data. The results showed that the paid plastic bag policy had the support of the local government, businesses and consumers. Various efforts have been made as a form of support to reduce waste generation in accordance with the objectives of this policy. Although consumers know and support this policy, it does not change consumer behaviour much. They still use plastic bags from retail when they finish shopping. Consumers have no objections to paying IDR 200. This policy does not bring many significant changes in consumer behaviour in using new plastic bags, despite the tendency of consumers to know the impact of plastic bag waste if it is not managed properly. Consumers still seem indifferent in considering plastic bag waste as an urgent waste priority. So that this policy is still less effective in changing consumer behaviour.
\end{abstract}

Keywords. policy implementation, paid plastic bags, environment

\footnotetext{
*Corresponding author: Muhammad.muslihun@gmail.com
} 


\section{Introduction}

Several studies related to plastic bag waste have been carried out by several researchers, for example in the study [2] the researchers measured the level of participation and effectiveness of the "No Plastic Day" program in changing community behaviour, the program succeeded in changing the community's perspective in the use of plastic bags. and can be said to be effective with the program can change people's behaviour in using plastic bags. Research on paid plastic bag policy in Indonesia, in (Saraswaty, 2018), the study measures the level of effectiveness in retail as a provider that the tendency in prices in the paid plastic bag policy has no significant effect on retail income economically and changes consumer behaviour in using plastic bags.

Plastic bags that are not managed properly can cause a variety of environmental and health losses. Therefore, the urgency of regulations and policies on the use of plastic bags needs to be supported by various parties. One such regulation is through various regulations and policies to minimize excessive use of disposable plastic bags. An environmental policy is needed to intervene and raise awareness of the impact of a future activity on the survival of the earth. Therefore, an evaluation of a policy is needed for policy improvement.

The study of the success and effectiveness of a policy needs to be further investigated to achieve the objectives to be achieved in a policy. Identification of factors and obstacles in a policy need to be examined to find the advantages and disadvantages of a policy. Policy implementation will be successful and effective if supported by implementers and target groups. The need for identification in a policy is to improve and increase the effectiveness of the policy. With the launch of the plastic pay policy is an effort to reduce waste generation. Therefore, in-depth research is needed to find the advantages and disadvantages of this policy. The implementation of the paid plastic bag policy is a policy that has the intent and purpose of reducing waste generation from waste-producing sources. The need for collaboration between various local governments, businesses and consumers in the effectiveness of this paid plastic bag policy. The objective of this study is to analyse the implementation of the paid plastic bag policy in the city of Semarang

\section{Research Methodology}

This study is to explore the details and characteristics of individuals and groups through indepth interviews. Data obtained from the results of the interview will be processed with descriptive analysis that is the description of words in detail and clearly (KBBI, 2001) in interpreting the results of interviews with informants in this study. The nature of this study is ex post facto with the aim of finding causes that are likely to be the basis of changes in behaviour, indications and phenomena that occur in an event in this study. Directly or indirectly the existence of an event will affect the behaviour of individuals and groups in addressing and acting.

\section{Result and Discussion}

\subsection{Factors that correlated}

\subsubsection{Supporting and Inhibiting Factors in Paid Plastic Bag Policy}

a. Increasing independence, community empowerment, and partnerships;

b. Developing the ability and community leadership;

c. Foster community responsiveness to conduct social supervision; 
d. Providing opinion suggestions;

e. Deliver information and / or submit reports.

\subsubsection{Source Factors}

The Semarang City Environment Agency has played an active role in promoting the policy of paid plastic bags in the city of Semarang through their available resources. With the support of businesses in implementing this policy in the city of Semarang. Adequacy of socialization through business actors should be able to have an impact on behaviour change to consumers in using new plastic bags. Business operators offer consumers new plastic bags by paying a nominal amount of IDR 200 as a substitute for new plastic bags that consumers use. This policy is a new policy, indirectly this is a socialization of a paid plastic bag policy to consumers.

\subsubsection{Factors of Trends}

As regulated in article 70 of Law Number 32 Year 2009 concerning Environmental Protection and Management, it is stated that the community has the same and broadest opportunity to play a role in environmental management by:

a. Increasing awareness in environmental protection and management;

b. Increasing the independence of community empowerment, and partnerships;

c. Growing the readiness of the community to conduct social supervision;

d. Develop and maintain a culture of local wisdom in the context of preserving environmental functions.

Although supported by stakeholders in this policy, namely the local government, business actors and consumers. This policy can be said to be less effective. According to consumer informants, this policy does not affect them in using new plastic bags from stores, this is because prices tend to be relatively cheap so consumers do not re-think in accepting new plastic bags from retail even though they have to pay. The purpose of the imposition of paid plastic bags is that consumers are expected to rethink using new plastic bags from retail so that the purpose and objectives of the policy in reducing waste generation can be minimized. There are trends in this policy considered less important, retail entrepreneurs who anticipate this policy will make consumers move places of shopping even though some studies say that consumers do not care about this policy because the prices they feel are still cheap.

\subsubsection{Bureaucratic Structure Factors}

Environmental management must be supported by funds with clear, transparent and accountable sources. The main source of funds in the management of the City of Semarang still comes from the provincial budget (Provincial APBD), while other sources are not yet available. Sources of funds can come from: State budget revenue (APBN); Provincial regional budget (provincial budget); District / city regional budget revenue (Regency / City. In this policy the obstacles faced in the implementation of the Paid Plastic Bag Policy in the City of Semarang are: limited implementation of instruments, limited ability of law enforcement officials, differences in perspective between law enforcement, lack of coordination between central and regional governments, lack of regulatory correctionally, lack of clear main content regulations rules. KLHK has not yet made a meaningful contribution to solving environmental problems. KLHK's lack of role in solving environmental problems is due to several things, namely: KLH does not have full authority over legal environmental management, unclear tasks, functions and authority between KLH 
and other agencies, both at the central and regional levels. Implementation of environmental management for the future needs to make changes to policies, improve environmental regulations and restructure the institutional management, namely by:

1. Preparation of the Paid Plastic Bag Policy program by implementing management principles that are holistic, integrated, multidimensional, multisectoral, multistakeholder and multi-stakeholder; Regional autonomy environment management policy is implemented as an alternative policy choice.

2. Improving the laws and regulations by involving all parties concerned; increasing the socialization of regulations to the public; and law enforcement through special environmental courts.

3. Restructuring of environmental management institutions at the central and regional levels that is integrated in accordance with environmental issues; clarify the duties, functions and authorities of each environmental institution to avoid duplication of facilities and infrastructure, as well as human resources in environmental institutions.

\subsection{Development Strategy for the Implementation of the Paid Plastic Bag Policy in the City of Semarang}

\subsubsection{Internal Analysis}

\section{Strengths}

1. Related Rules Regarding Waste Management

The basis in this plastic pay policy is Law No. 18 of 2018 concerning Waste Management and Government Regulation No. 81 of 2012 concerning Management of Household Oath and Household Waste.

2. The issuance of Mayor Regulation No.27 of 2019

In order to increase public awareness to create a clean, beautiful and healthy environment, community participation and / or business actors are needed. The use of plastic in the form of plastic bags, plastic drinking pipettes, styrofoam has become a problem in the city of Semarang, so it needs to be done to control the impact of the use of plastic. The urgency of managing plastic control in the mayor's regulation is one of the efforts to control plastic waste that circulates in the city of Semarang.

3. Get support from business actors

One of the targets to support this policy is businesses, as providers of plastic bags to consumers. The role of business actors is very important in promoting and campaigning for this policy program. Through business actors, consumers as end users of plastic bags can find out the purpose and objectives of implementing this policy.

4. Enhance Pro-Environment Attitudes

The purpose and objective of the paid plastic bag policy is to reduce waste generation in sources of waste generation and the use of plastic shopping bags through the application of non-free disposable plastic shopping bags. So that the pro-environment attitude of consumers in the use of plastic bags can be intervened.

Weaknesses

1. Optional Policie

The scope of the application of the paid plastic bag policy is carried out by retail / modern stores that stand alone and are in the shopping library.

2. There is no compulsion in the application of the paid plastic bag policy, but most modern retail / shops participate in the policy. After the trial of the paid plastic bag 
policy, retail / shops again give / sell plastic bags to consumers for free. Sustainability of this policy becomes the preference of every retail / store after further regulation through respective local government regulations.

3. Only applies to retail / modern stores

The pay plastic bag policy is only applied to retail / modern stores. Stores that are not in that category do not participate in this policy. Such as traditional markets, grocery stores, and other stores. So, this policy seems uneven.

4. Pricing Tends to Be Relatively Cheap

Determination of the price of IDR 200 that tends to be relatively cheap so that people do not pay too much attention to the small nominal. Perceptions of policies are felt to be less stimulating to the public / consumers in considering the use of new plastic bags. Price is a factor that can change consumer behaviour in terms of the use of plastic bags.

5. The absence / absence of periodic monitoring

In the implementation regulation of this policy / retail circular letter is required to report the outcome of this policy. Each retailer reports the use of plastic bags and the activities carried out, to the Ministry of Environment and Forestry (KLHK), with a copy to the local governor, mayor / regent. Monitoring is needed as an evaluation material for policies related to this circular in the future. Monitoring in the form of the use of plastic bags by consumers and consumer responses in response to this policy.

\subsubsection{External analysis}

\section{Opportunities}

1. Reducing the burden of teak landfills (TPA)

Jatibarang landfill (TPA) is a place where Semarang municipal household waste ends. With the current pattern of waste management, the estimated lifetime of the landfill will not be long. If this policy goes well the TPA lifetime will be longer.

2. Economic value for the "reusable bag" industry

As an alternative to grocery bags, the public / consumers can buy reusable bags. The reusable bag creative industry can grow along with this policy, the need as an alternative bag for carrying consumer goods.

3. Increase consumer awareness in choosing environmentally friendly products

The best choice in reducing the use of plastic products is to choose alternative products that are environmentally friendly. If the effort in minimizing cannot be done. Awareness in choosing products that are safe for the environment can accustom community behaviour to be pro-environment for sustainability.

4. Minimize the use of plastic bags

The best effort in managing waste in the hierarchy, including the plastic bag itself as a carrier of groceries, is to prevent using plastic bags when considering environmental impacts. Because of the decomposition of plastic bags like other plastics that are difficult to decompose naturally in nature, other than that other living things such as animals can be threatened if consuming plastic bags that are not managed properly. Minimizing the use of new plastic bags from retail can be prevented by the awareness of consumers carrying alternative shopping bags other than plastic shopping bags. If consumers bring alternative bags, the demand for plastic bags from retail will decrease.

Threats

1. Only applied for certain retails / places 
Not all places / retailers that provide plastic bags apply this policy, in the scope of the paid plastic bag policy only rite / modern is the target of this policy. Traditional retail / shops do not participate. So that the tendency of consumers who shop traditional retail does not know the intent and purpose of this policy. Most consumers get paid plastic bag policy information through their retail shopping. Although in addition to reducing waste generation, the purpose of this policy if it is disseminated massively will have an impact in educating the public.

2. The community does not consider plastic waste as a management priority

The need for management of plastic bag waste needs to be improved by all stakeholders. Education on plastic waste management needs to be improved for the whole community and consumers. As a form of anticipation in overcoming the plastic bag waste generation.

3. There is no periodic control and supervision by the Regional Government (related agency)

In this case the relevant agencies in the regional government in question are the Office of the Environment (DLH), Satpol PP, tourism and trade services. Retail information will not be monitored by the local government, only the socialization of the application of this policy is carried out through DLH.

4. Consumers still want to pay

The price of each new plastic bag requested by consumers is IDR 200, according to consumers, the price is still considered cheap so consumers ignore the price. Consumers are still willing to issue a nominal Rp.200 for new plastic bags from retail. The price which tends to be cheap makes consumers not care about using plastic, it is possible that if the price of plastic bags offered is expensive, consumers will consider the use of new plastic bags from their shop.

\section{Conclusion}

The factors that become obstacles and supporters in controlling the management of plastic bag waste are;

\subsection{Supporting factors}

1. Specific regulations have been issued to reduce the use of plastics, namely styrofoam, pipettes and plastic bags as outlined in local regulations, Mayor Regulation No.27 of 2019.

2. Circular mayor has been distributed related to the mayor's regulations through Mayor Circular Letter Number; 660.1 / 4910 regarding controlling the use of plastics.

3. The Semarang City Environment Agency (DLH) as part of the local government has synergized with related agencies to reduce the use of plastic bags as a form of urgency for the problem of plastic waste which is still a problem.

\subsection{Inhibiting factors}

1. The pro-environment attitude of consumers / communities is still lacking, an indication of this is that they are still willing to pay for plastic bags and deliberately do not bring their own plastic bags because the price in the application is still felt by consumers / the public is cheap. 
2. Periodic monitoring from related agencies is not yet available to monitor the implementation of this regulation.

3. The application of this policy is still optional. Retailers may apply this policy or do not apply.

4. The price of setting plastic bags that are cheap enough causes consumers not to think twice about using new plastic bags.

5. Lack of monitoring from the central and regional governments in implementing the paid plastic bag policy and the mayor's regulation on controlling the use of plastic.

6. Sanctions that have not yet been applied to retailers / business actors who still provide plastic bags.

\section{References}

1. Adane, L. and Muleta, D. 'Survey on the usage of plastic bags, their disposal and adverse impacts on environment: A case study in Jimma City, Southwestern Ethiopia', Journal of Toxicology and Environmental Health Sciences, 3(August), pp. 234-248. (2011).

2. Asmuni, S. et al.. 'Public Participation and Effectiveness of the no Plastic Bag Day Program in Malaysia', Procedia - Social and Behavioral Sciences. Elsevier B.V., 168, pp. 328-340. doi: 10.1016/j.sbspro.2014.10.238.(2015)

3. Ayalon, O. et al., 2009. 'Reduction of plastic carrier bag use: An analysis of alternatives in Israel', Waste Management. Elsevier Ltd, 29(7), pp. 2025-2032. doi: 10.1016/j.wasman.02.016.(2009)

4. Bashir, N. H. H... 'Plastic problem in Africa', Japanese Journal of Veterinary Research, 61(SUPPL.). doi: 10.14943/jjvr.61.suppl.s1.(2013)

5. Basili, M., Di Matteo, M. and Ferrini, S. 'Analysing demand for environmental quality: A willingness to pay/accept study in the province of Siena (Italy)', Waste Management, 26 (3), pp. 209-219. doi: 10.1016/j.wasman.2004.12.027.(2006)

6. Bearden, H Joe, John W Fuquay, dan Scott T. Willard.. Applied Animal Reproduction. Upper Saddle River : New Jersey. (2004)

7. Boztepe, Aysel.. Green marketing and its impact on consumer buying behaviour. European Journal of Economic and Political Studies. (2012)

8. Dikgang, J., Leiman, A. and Visser, M.. Analysis of the plastic-bag levy in South Africa, Resources, Conservation and Recycling. Elsevier B.V., 66, pp. 59-65. doi: 10.1016/j.resconrec.2012.06.009.(2012)

9. Hoegh-Guldberg, O. . et al., 2015. 'The ocean', Climate Change 2014: Impacts, Adaptation and Vulnerability: Part B: Regional Aspects: Working Group II Contribution to the Fifth Assessment Report of the Intergovernmental Panel on Climate Change, (January), pp. 1655-1734. doi: 10.1017/CBO9781107415386.010.(2015)

10. Hyman, M., Turner, B. and Carpintero, A. Guidelines for National Waste Management Strategies: Moving from Challenges to Opportunities, The Inter-Organisation Programme for the Sound Management of Chemicals (IOMC). doi: ISBN 978-92-8073333-4.(2013)

11. Jakovcevic, A. et al. 'Charges for plastic bags: Motivational and behavioral effects', Journal of Environmental Psychology. Elsevier Ltd, 40, pp. 372-380. doi: 10.1016/j.jenvp.2014.09.004.(2014)

12. Jalil, M. A., Mian, M. N. and Rahman, M. K..'Using Plastic Bags and Its Damaging Impact on Environment and Agriculture: An Alternative Proposal', International Journal of Learning and Development, 3(4), p. 1. doi: 10.5296/ijld.v3i4.4137.(2013) 
13. Jambek, Jenna $\mathrm{R}$ et al. Plastic Waste Inputs Into the Ocean. Science 347. DOI; 10.1126/science.1260352. (2015)

14. Lindblom, Charles E. The Policy Making Process. London : Prentice Hall. Liobikiene, Genovaite, Justina Mandravickaite, dan Jurga Bernatoniene. 2016. Theory of planned behaviour approach to understand the green purchasing behaviour in the EU: a crosscultural study. Journal Ecological Economics 125 (2016) 38-46. (1980)

15. Musa, H. M. et al. 'Measures Aimed at Reducing Plastic Carrier Bag Use: A Consumer Behaviour Focused Study', Natural Environment, 1(1), p. $17 . \quad$ doi: 10.12966/ne.06.02.2013.(2013)

16. Ohtomo, S. and Ohnuma, S. 'Psychological Interventional Approach For Reduce Resource Consumption: Reducing Plastic Bag Usage At Supermarkets', Resources,

Conservation and Recycling. Elsevier B.V., 84, pp. 57-65. doi: 10.1016/j.resconrec.2013.12.014.(2014)

17. Suki, Norazah Mohd..2013. Green awareness effects on consumers' purchasing decision: some insights from Malaysia. Universiti Sains Malaysia, Vol. 9, No. 2, 49-63.

18. Unep.Valuing Plastics: The Business Case for Measuring, Managing and Disclosing Plastic Use in the Consumer Goods Industry. Available at: www.unep.org/pdf/ValuingPlastic/.(2014)

19. Vicente-Molina, M. A., Fernandez-Sainz, A., dan Izagirre-Olaizola.. Environmental Knowledge and Other Variables Affecting Pro-Environmental Behaviour: Comparison of University Students from Emerging and Advanced Countries, Journal of Cleaner Production 61: 130-138.(2013)

20. Zhu, Q.. 'An appraisal and analysis of the law of "'Plastic-Bag Ban", Energy Procedia, 5, pp. 2516-2521. doi: 10.1016/j.egypro.2011.03.432.(2011) 